\title{
Designing and Using Geometry Case Studies in the Last Grade at Secondary Schools by Integrated Teaching Method in Vietnam
}

\author{
Tran Viet Cuong ${ }^{1, *}$, Dao Tam ${ }^{2}$, Pham Van Hieu ${ }^{3}$ \\ ${ }^{1}$ Thai Nguyen University of Education, 20 Luong Ngoc Quyen, Thai Nguyen City, Thai Nguyen Province, Vietnam \\ ${ }^{2}$ Vinh University, Vinh City, Nghe An Province, Vietnam \\ ${ }^{3}$ Department of Education and Training, Hong Bang District, Hai Phong City, Vietnam
}

Received August 22, 2020; Revised October 19, 2020; Accepted October 24, 2020

\begin{abstract}
Cite This Paper in the following Citation Styles
(a): [1] Tran Viet Cuong, Dao Tam, Pham Van Hieu, "Designing and Using Geometry Case Studies in the Last Grade at Secondary Schools by Integrated Teaching Method in Vietnam," Universal Journal of Educational Research, Vol. 8, No. 12, pp. 6620-6634, 2020. DOI: 10.13189/ujer.2020.081226.
\end{abstract}

(b): Tran Viet Cuong, Dao Tam, Pham Van Hieu (2020). Designing and Using Geometry Case Studies in the Last Grade at Secondary Schools by Integrated Teaching Method in Vietnam. Universal Journal of Educational Research, 8(12), 6620-6634. DOI: 10.13189/ujer.2020.081226.

Copyright $\subseteq 2020$ by authors, all rights reserved. Authors agree that this article remains permanently open access under the terms of the Creative Commons Attribution License 4.0 International License

\begin{abstract}
The objective of the study to evaluate the effectiveness of lectures designed and applied integrated teaching methods for geometry in grade 9 . We conducted research with 10 teachers and 154 students in both experimental and control classes (Grade 9). The tools used include: integrated lesson plans that are selected for the topic (circle) and taught in a period of 3 weeks. Firstly, we designed integrated teaching case studies through two examples, followed by a specific example that will guide teachers to integrate Mathematics in Grade 9. To evaluate research results, we used a carefully designed Rubric to evaluate the teacher's Math teaching process; SPSS version 20 software helps us compare students' Math learning results between experimental and control classes. We have found that there is a significant increase in students' Math performance in terms of how they perceive knowledge, apply knowledge to solve life situations, narrow the gap between math and life situations, increase motivation and increase student flexibility in problem solving.
\end{abstract}

Keywords Practical Situations, Integrated Teaching, Geometry, Secondary Schools

\section{Introduction}

In recent times there has been a cross-disciplinary amplification of interest in the concept of practice [1]. Rawlins, Glenda Anthony, Robin Averill \& Michael Drake [2] stated that while there is a broad evidence base about what constitutes effective mathematics teaching in schools, less is known about how to effectively prepare novice teachers to teach in a project designed to support novice teachers to become "ambitious" mathematics teachers by utilising practice-based approaches. Knowledge transmission and knowledge construction are two common approaches adopted for teaching and learning [3].

Benbow, Ronald M. [4] stated that students often care about the problems they learn, which affects their decisions in learning math and their mathematical achievement. Similarly, the authors [5], [6], [7], [8], [9]) point out that the nature of teachers' beliefs about this and the teaching and learning can also play an important role in shaping their teaching activities. According to many experts, exploring the ways in which high school math teachers bring new meaning to the development of general education [37, 38, 39, 40], Tran Viet Cuong said that learning and life are not separate; recently teachers need to guide students how to learn and how to handle situations in real contexts [41].

In this context, there is a growing body of research considering how teaching and teacher education might be viewed using the conceptual lens of practice [1], [10], [11], [12]. 
An integrated curriculum allows students to pursue holistic learning, not limited by subject boundaries. Elementary and secondary school programs focus on the relevance of all extracurricular areas in helping students acquire basic learning tools.

Projects and topics are valuable teaching tools to provide for all learners in the classroom. Skills are taught when needed to complete projects [13], [14]. Some design for supporting theory-practice is reflected in teacher practicums [15].

Integrated teaching is an orientation in educational innovation, a step from teaching with content-based to capacity-based approach to train dynamic, creative and capable people to apply knowledge in solving problems in real life. Integration is a key word in teaching. It is an approach to teaching and learning based on a wide range of disciplines, disciplines and practices, in which students develop their ability to seek knowledge from open sources without being confined to internal mathematics [16].

Integration includes the purpose of gathering knowledge, skills, attitudes and values from inside or outside the object to develop a stronger understanding of key ideas. Integration occurs when the components of the curriculum are connected and related in meaningful ways by students, teachers, experts ... accordingly, many fields or content of the curriculum will be connected usually in a topic or project. Integration is not a new way of organizing teaching According to many documents, the concept of curriculum integration has been talked about since the 1890s. Over the years, many educational researchers, such as Susan Drake, Heidi Hayes Jacobs, James Beane and Gordon Vars have described different interpretations of integrated curriculum, referring to interconnected, thematic, interdisciplinary, relevant, interconnected and comprehensive curricula. Some educators, such as, Robin Fogarty did not mention it as a single definition but see it as a continuum. The key word "integration" expresses how to connect the subjects in the curriculum, especially on the topics of the program in general and in elementary schools in particular.

Integrated teaching is the right direction, as a means by which students can develop deep, interconnected knowledge structures. Integrated teaching helps learners to develop their competencies; this method makes students active and creative. Students have more motivation in learning [17].

Katariina Stenberg, Antti Rajala \& Jaakko Hilppo [15] stated that their theory-practice connections were more robust than those made by student teachers who participated in the conventional practicum. Integrative learning focuses learners on making connections across knowledge domains, various contexts and time [18]. Integrated teaching means helps us to find the relationship between these knowledge, methods and other ones [17]. However, the author JS Pang, R Good [36] said that explicitly defining "intergrated teaching" is very difficult; many terms are often used to refer to the combination.
Domestic and foreign studies have shown that integrated teaching will help students build competencies, including the ability to apply knowledge to solve problems, especially apply knowledge to practice [19] because problems that arise in life and production are rarely related to a specific field of knowledge but often require the combined application of knowledge in a number of different subjects and disciplines. It means that secondary education must help students have a view of the world in its inherent unity, not divided, separated into each subject, each field too early.

Valoyes-Chávez [9] khám phá những cách thức mà giáo viên dạy toán ở trường trung học mang lại một ý nghĩa mới cho giáo viên dạy toán trong bối cảnh các chương trình phát triển chuyên nghiệp nhằm thực hiện các hướng dẫn giải quyết vấn đề.

\section{Literature Review}

Integrated teaching has trend for a modern, learner-centered. Today, Vietnam is strongly innovating from teaching academic knowledge to integrated teaching [17]. According to the General Education Program (2018) [20], issued by the Ministry of Education and Training, integrated teaching is a teaching orientation that helps students develop their ability to mobilize general knowledge, skills, ... in many different fields to effectively solve problems in learning and in life in the process of acquiring knowledge and training skills [20], [41], [42]. Novice teachers' support for rehearsals for developing their mathematical pedagogical skills is presented alongside implications for instructional reforms within mathematics methods courses [2].

The definitions and concepts of integrated teaching by the authors all consider integrated teaching as an orientation in educational innovation, a step from teaching with content-based approach to competence-based approach in order to train people to be active, creative and capable of applying knowledge when solving problems in real life. Zeynep Çiğdem Özcan [21] state that, studies highlight that using appropriate strategies during problem solving is important to improve problem-solving skills.

Analyzing the theoretical basis of integrated teaching and considering the integrated teaching perspectives in the world and in the country, we offer the following conception of integrated teaching in Mathematics: Teaching integration in Mathematics in secondary school is a teaching style in which students acquire knowledge and skills on the basis of interacting with teaching situations that meet the following requirements:

1. Situations designed by teachers from the knowledge of mathematics. The knowledge of other related subjects or practical situations can be exploited to formulate, consolidate and deepen mathematical knowledge [22], [23]; 
2. Situations for solving a mathematical problem through modeling activities in other subjects or in practice [24];

3. Situations can be explained by known mathematical knowledge or knowledge of other related subjects; situations allow the connection of mathematical knowledge with the knowledge of other sciences;

4. By solving situations students grasp the meaning of the mathematical knowledge.

In the 2018 General Education Program, the Math curriculum implements interdisciplinary integration through related content, topics or mathematical knowledge exploited and used in other subjects such as Physics, Chemistry, Biology, Geography, Informatics, Technology, History, Art ... Exploiting well the interdisciplinary factors mentioned above effectively contribute to consolidating Math knowledge as well as train students the ability to apply math in practice.

The Geometry and Measurement content at secondary school in 2018 general education program includes Visual Geometry and Flat Geometry. Visual geometry provides language, symbols and descriptions (at a visual level) of objects in reality (flat, solid), create some common geometric models, calculate some geometric factors, develop spatial imagination, and solve some simple practical problems associated with Geometry and Measurement. Flat geometry provides the knowledge and skills (at the logical level) of geometric relations and some common Flat Geometry (points, lines, rays, straight lines, angles, two parallel lines, triangle, quadrilateral, circle) [20].

Researching the teaching of integrated mathematics in secondary schools in general and teaching integrated geometry in particular, we have found that it is not easy to formulate integrated teaching topics in mathematics and mathematics with other science subjects, Math with practice. Moreover, the organization of learning activities for students to implement integrated topics of teachers still faces many difficulties.

Therefore, in order to contribute to improving the effectiveness of the implementation of the 2018 general education curriculum, we provide a process of designing and implementing geometry teaching situations in the last grade at secondary school in the direction of integrated teaching.

\subsection{The Process of Designing Geometry Teaching Situations in the Last Grade at Secondary School}

The process design activity is the study of teachers' lessons through their experience activities. We clarify the process in the order of the following steps:

Step 1. The teacher studies the content and core objectives of the lesson

In this step, the integrated teaching needs to ensure deepening the content of teaching, clarifying the teaching objectives, especially, the objective of implementing the principle of "ensuring the sequentialness in teaching mathematics", the prior knowledge for later learning, ensuring the close relationship in the system of knowledge, paying attention to causal relationship, dependent relationship, focusing on the goal of connecting math education with practice. This step is aimed at helping teachers see the basis for detecting real-life situations that contain knowledge related to the knowledge to be taught, and also to guide teachers in lesson study.

Step 2. Explore to find situations selected from related knowledge content or from other subject knowledge, practical situations that contain knowledge related to the content to be taught

This step clarifies how math is connected to reality. The teacher needs to study to find out situations from mathematics, from the relationship between mathematics and other sciences. Finding situations that come from other sciences or real-life situations are in fact exploring the origin of mathematical knowledge, exploring the role of mathematical knowledge in other subjects, exploiting applications of mathematical knowledge in real life. In addition to the above implications of the implementation integrated teaching perspective, the survey through practical situations, situations based on knowledge of other sciences encourage teachers and students to find general knowledge and common things. Finding new things must start from reviewing, researching and surveying specific cases.

Step 3. Organize seminars in professional groups and consult experienced teachers directly or via other communication media

This step is an important step in studying the lesson in teaching geometry at the last grade in secondary school with an integrated perspective. The study of the lesson means " Teachers come together to share common questions about students' learning, planning a lesson, teaching activities, testing and discussing what they observe from students' math performance. Through the iterative process, teachers have many opportunities to discuss student learning and how their teaching affects students.

If teachers have opportunities to present in scientific seminars, listen to experienced teachers through direct exchange or through the media, they have the opportunity to interact and get more experience in experiential exploration of integrated teaching situations. Sometimes through opinions in seminars, and opinions of experienced people, the designed cases will ensure organizational requirements for practical situations, and teachers have a basis to choose typical situations for students to interact. Discussion and interaction activities in the process of finding situations will contribute to the development of teachers' practical skills in integrated teaching and improve 
the theoretical knowledge of integrated teaching. This is consistent with the study of thinking development: Thinking is from the outside in, initially through social interactions and communication activities, and then begins to focus on the inside through key activities such as analysis, generalization, and abstraction.

Step 4. Observing students, groups of students through interaction with situations to detect students' level of awareness

This step is to understand the following key issues as a basis for student feedback, from which the teacher adjusts the designed situations by adding specific questions in order for students to interact, conducting a consideration of lowering the requirement or raising the required interact level in accordance with the student's cognitive level. Also, in this step we explore the advantages and disadvantages of students in interacting in situations to explore, inculcate, and exploit applications of knowledge.

Step 5. Complete the situation after having students feedback on levels of cognitive activity: Generalizing, abstracting, modeling

This step is the final step of exploring and designing integrated teaching situations. It is the result of teacher experience activities in the preparation of teaching lessons from an integrated approach point of view. Situations should ensure the necessary theoretical basis and the operational basis of the teacher.

\subsection{The Process of Applying Integrated Teaching for Geometric Situations in the Last Grade of Secondary School}

After the process design, the teacher teaches according to the designed process. In order to carry out the above design process, we study the process of applying the designed situations. In the application process, it is necessary to consider the appropriate use of teaching methods and teaching theory to each part to be taught in an integrated perspective. The main methods used to implement teaching in integrated situations designed in this study include: Teaching from the perspective of operational theory, teaching problem solving, cooperative teaching, teaching from the perspective of constructivist theory. These are teaching perspectives that have been paid much attention in theoretical and practical research on mathematics education in our country.

Depending on the level of use of the methods in the application process, it is necessary to clarify the key activities of the teacher and the student's activity in the process of interacting with integrated situations.

The steps of the process of applying integrated situations in teaching geometry at the last grade of secondary school are as follows:
Step 1. Transferring cognitive tasks to students by giving appropriate integrated situations to the content and objectives of the geometry subject to be taught

The nature of this step is that a teacher assigns cognitive tasks to students so that they can be familiar with an integrated perspective. "The essence of teaching mathematics is to teach mathematical thinking". This view is interested by many educational researchers and pedagogists such as G.Polya, Nguyen Ba Kim, Dao Tam ... In cognitive theory, it is clear that thinking only begins when one is facing a cognitive task such as a difficulty, an obstacle, a mistake, or contradictions that need to be resolved and overcome. To clarify the cognitive task at this step teacher need to make students understand what is the problem posed in a situation to solve? The problem is that what difficulties, obstacles in integrating knowledge from internal math, from knowledge of other subjects and practice [25]. We argue that reform in curriculum and instruction should be based on allowing students to problematize the subject [26].

Step 2. Organize activities for students to interact in situations according to the system of questions or teacher orientation (in class, in groups or in extra-curricular activities according to requirements, level of cognition of the topic to be taught) in order to discover concepts and clauses, make predictions hypotheses and patterns of phenomena

To accomplish this step the teacher studies the situations in order to provide a system of questions and instructions that address the following goals:

- Let students purposefully observe and reveal the essential attributes of mathematical objects hidden in situations, gradually expose the regular relationships between mathematical objects or make appearances step by step mathematical models of practical phenomena by roughing phenomena and ignoring non-essential properties.

- Direct students into integrated comparative analysis to make conclusions about the intrinsic properties of phenomena, make judgments about propositions, laws, and mathematical models of common phenomena through activities of generalization, abstraction, and idealization.

Step 3. Ask students to argue proving the statements, reasoning test hypotheses, solving problems in the model

In this step, we emphasize the activities of teachers and students. Teachers observe the activities of groups of students in the process of solving problem; consider giving directions and instructions, answer questions when students encounter difficulties or obstacles; detect students' mistakes to promptly correct; let students or groups present steps to solve problems, test hypotheses, solve problems in the model. 
Step 4. Let students make conclusions about concepts, clauses, and meanings of knowledge drawn from mathematical models, and give directions for developing new problems. Teachers affirm the above knowledge

Teacher and students' activities shown in this step include: The teacher makes conclusions about students' solutions, ways of testing hypotheses, arguments on their guesses, and practical meaning when solving problems in a model. The teacher asks students to give directions to develop math tasks and develop problems into new ones, which are intended for home study or online discussion, to enhance student interaction activities. Pupil's capabilities were seen to be enhanced through their direct, active, socio-cultural interactions, within a range of classroom settings, and involving different teaching methods [28].

\section{Research Methods}

\subsection{Design and Procedure}

The study was conducted at a random Nguyen Trai secondary school, Hong Bang district, Hai Phong city, Vietnam. 154 secondary school students participated in the study.

The research team will select 2 experimental classes and 2 control classes (all in Grade 9). In the school, each class of grade 9 is coded on identical pieces of paper by the research team, and then it was fold and put in a sealed box. Then the pieces of paper were mixed in the sealed box. Someone else will take any first 2 pieces of paper to confirm the experimental classes, and then take the 2 other pieces of paper to confirm control classes. This random sampling method resulted in the selection of four classes. Statistics in Maths, SPSS version 2.0 software help the research team evaluate Math learning results among students testing the integrated teaching method with students learning with traditional methods.

The experimental and controlled classes have almost no change in teaching plans, because according to our understanding, the Board of Rector does not want to have an adjustment to the school schedule.

\subsection{Material Used}

The time table is exchanged by the research team with math teachers and administrators, in order not to affect the general learning activities of the school and the classroom. We are suggested to do it in 3 weeks and in the Math lessons have been set according to the schedule from the beginning of the school year (from May 4, 2020 to May 22, 2020).

Research teams and teachers taught students about topics for three weeks respectively. The materials used are as follows:

1. A work plan consisting of integrated teaching lesson plans of the selected topic (circle) was conducted over a three-week period. The students had not been discussed on these topics by teachers prior to the lesson.

2. Giving a guideline on the process of designing geometry teaching situations in the last grade of secondary schools (see example 1 and example 2).

3. Giving a guideline on the process of applying integrated teaching to geometrical situations in the last grade of secondary schools, the lecture with instructions (see example 3).

4. A Rubric is meticulously designed to evaluate a teacher's Math teaching process. Criteria self-assessment guides are used differently in the different evaluation stages (see Table 1).

5. Giving a set of 40 multiple-choice questions on the topics covered

Table 1. Rubric for self-assessment of teachers to evaluate maths teaching activities

\begin{tabular}{|c|c|}
\hline \multirow{2}{*}{ Score } & Brief description \\
\hline & Criteria \\
\hline Excellent & $\begin{array}{l}\text { Mission completed, using the strategies / or making the interpretations come to life, go beyond the } \\
\text { requirement for the methods assigned for this level. }\end{array}$ \\
\hline Good & $\begin{array}{l}\text { Mission completed. Central mathematical ideas expressed clearly and understood. There is a connection } \\
\text { with life sometimes. }\end{array}$ \\
\hline Average & $\begin{array}{l}\text { Make significant progress to complete missions; instruction on understanding of relevant knowledge, } \\
\text { concepts and skills have been given; however, some key ideas are lacking. }\end{array}$ \\
\hline Need to keep trying & $\begin{array}{l}\text { Trying to complete teaching tasks with traditional methods; students are forced to absorb knowledge; } \\
\text { students are able to partially capture but limited main mathematical ideas; It is impossible to find the } \\
\text { applicability of mathematics in practice. }\end{array}$ \\
\hline \multicolumn{2}{|r|}{ Tr } \\
\hline
\end{tabular}


It is used as pre-test, post-test, and delayed posttest to evaluate student performance. The tests were selected from the previous Secondary School Exam questions. The questions were standardized in nature, as the questions were written by test and measurement experts experienced in the drafting the general education program in Vietnam. To confirm the reliability of the tests, performance tests were administered to a group of 154 students.

The following are illustrative examples of how to design and apply integrated teaching in geometrical situations [29]; [30].

Example 1. The concept of a circle was taught in grade 6 and repeated in grade 9. "In flat geometry, a circle is a collection of all points on a plane, equidistant from a given point by any distance. The given point is called the center of the circle, and the given interval is called the radius of the circle". To implement this conceptual teaching by inductive path in an integrated approach, the following specific practical situations should be given and guided for students to carry out observing, comparative analysis, review, and finally abstraction to get the concept of a circle.

Teachers let students observe visual Figures of a clock and bicycle rim (Figure 1 and Figure 2).

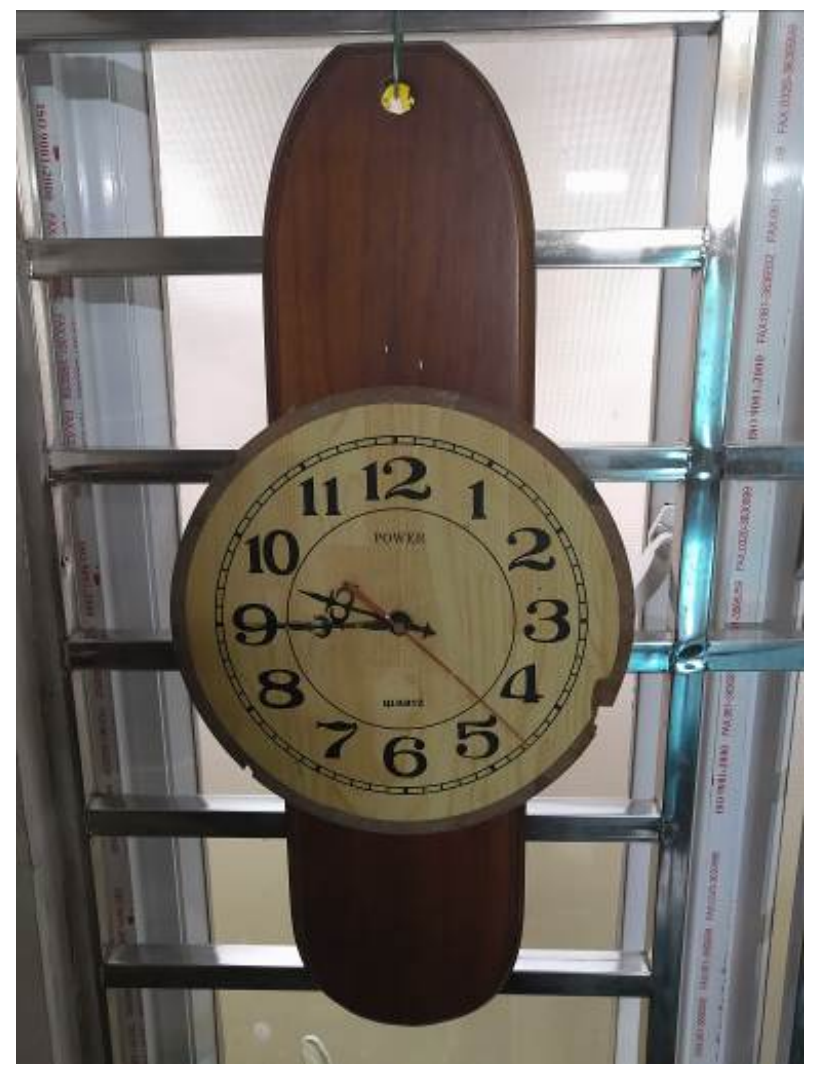

Figure 1. Clock model and circle

Next, the teacher can orient the students to observe following these questions:

Observe the movement of the second hand (figure 1), observe the top and the end of the second hand and the center circle close to the end of the second hand; and observe the movement of the other end of the second hand.

Expected answer: One end of the second hand is attached to a fixed shaft; one moves in a circle.

The teacher let the students observe and answer the teacher's question: "When the second hand moves, what are your comments about the distance from the fixed axis to the points on the circle?"

Expected answer: This distance is constant and exactly equal to the length of the second hand.

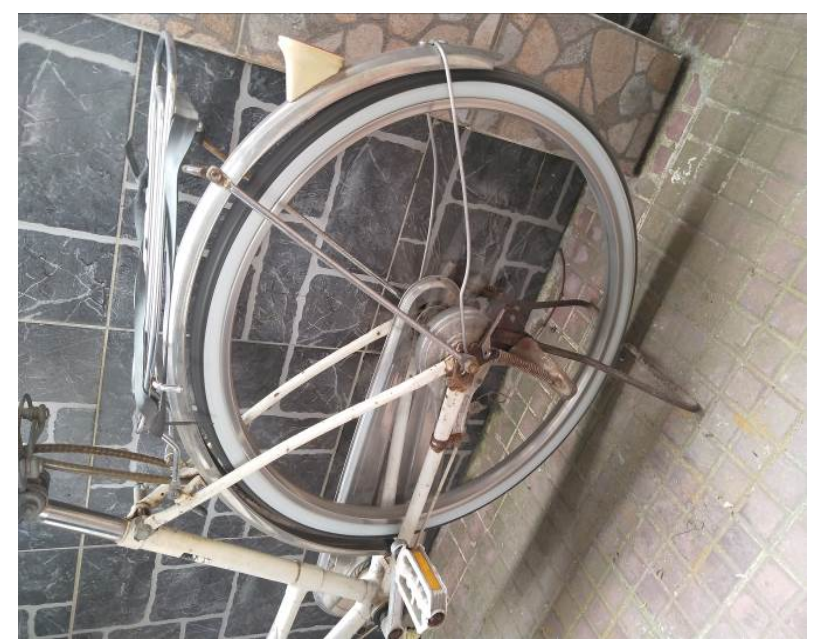

Figure 2. Bicycle rim model and circle

Next, the teacher let students continue to observe the rim of the bicycle wheel (Figure 2) and direct the students to look intentionally through the following questions: The rim is attached to the spoke and the other end of the spoke is attached to the bike hubs. What is the characteristic of the distance from the bicycle hubs to the rim of the bicycle at the different points?

Expected answer: The distance is equal and equal to the length of the bicycle spokes.

The teacher asks a question: "The line is close to the end of second hand, and the rim of the bicycle wheel has a circular shape. So can you state the definition of a circle?"

After the students' response, the teacher adjusts the students' answers to come up with the definition of a circle. The student's statement of definition is essentially the result of the act of abstraction

Choosing specific visual items such as clocks, bicycle rims or other real performances should be discussed carefully at the seminar of the professional group, through discussions with experienced teachers. In the above example, we are only interested in the teacher's choice of situations through research on the concept of a circle. (Cai, J., Nie, B. [24] stated that problem solving has been viewed both as an instructional goal and as an instructional approach.

Example 2. We consider a few selected design situations in review teaching to exploit the application of Pythagorean Theorem and find new rules.

Situation 1. Given 2 squares assembled with 4 square tiles and 9 square tiles (Figure 3). 
Teachers let students observe and answer the following questions:

Please count the number of tiles on each side and on the diagonal of the square in Figure 3 and Figure 4 and compare the results.

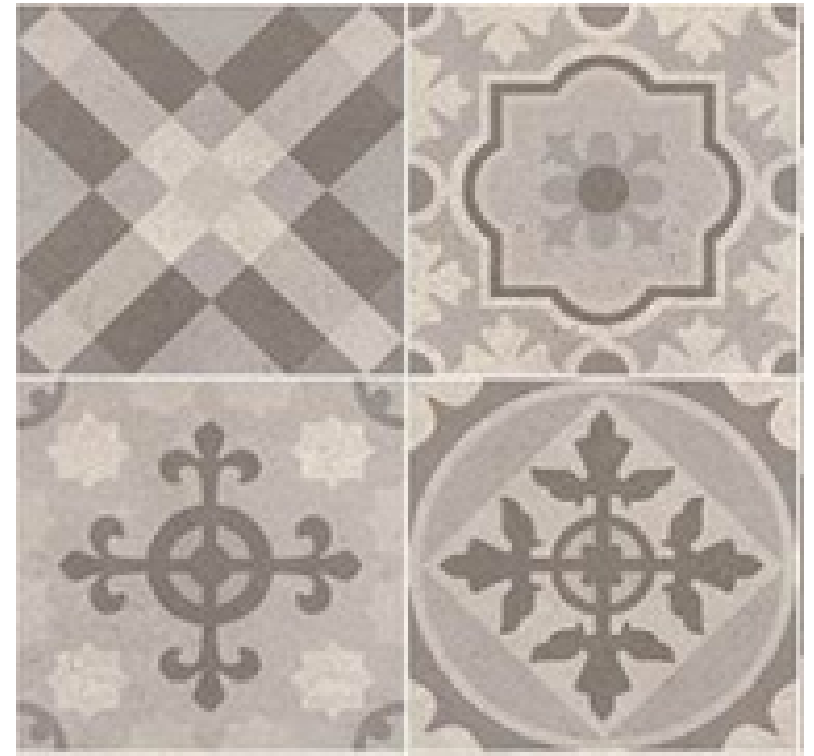

Figure 3. Square assembled with 4 square tiles

Expected answer: The number of tiles on the side and the number of tiles on the diagonal of Figure 3 are equal. The same goes for figure 4: The number of tiles on the side is 3 and the number of tiles on the diagonal is also equal to 3 .

Using the knowledge you learned, please explain the results above, and state general propositions.

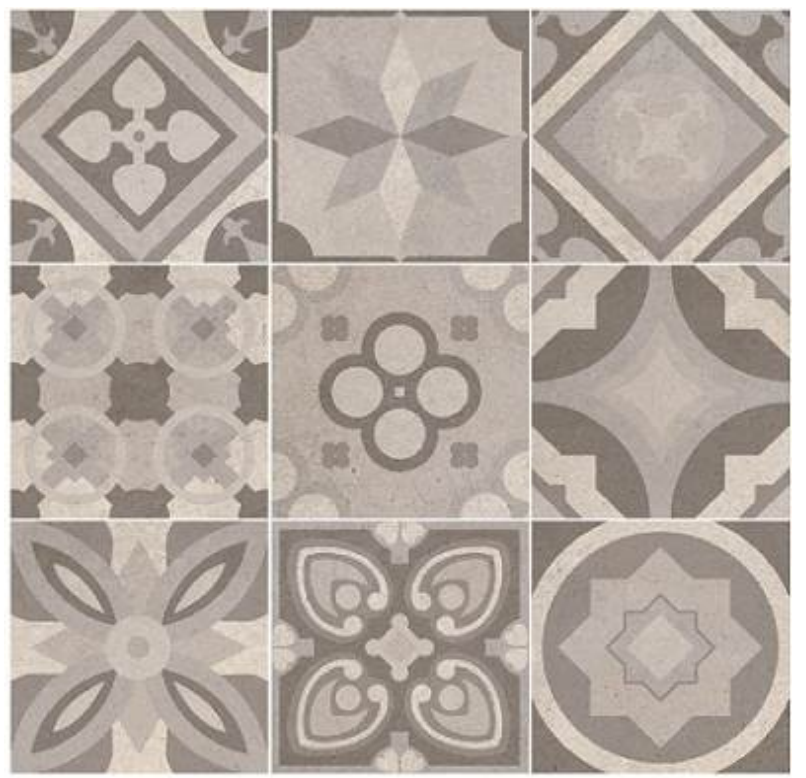

Figure 4. Square assembled with 9 square tiles
Expected answer: In the case of a square, which is arranged by 9 square tiles of equal size?

Assuming is one side of a square tile, and then the big square side length is $3 \mathrm{a}$ and the diagonal length $(\mathrm{x})$ of the square is calculated according to Pythagorean Theorem:

$$
x^{2}=(3 a)^{2}+(3 a)^{2}=18 a^{2} \Leftrightarrow x=3 \sqrt{2} a .
$$

Since the length of each diagonal of the square tile is $a \sqrt{2}$, the diagonal of the big square in Figure 4 contains 3 diagonal of the 3 tiles. In other words, the number of tiles on the diagonal of Figure 4 is equal to the number of tiles on one side of the square.

Then, the teacher assigns the tasks for students to experience, explore the applications of Pythagorean Theorem and develop a new problem by explaining the following situation:

Situation 2. Figure 5 shows a square made up of $n^{2}$ square tiles of the same size.

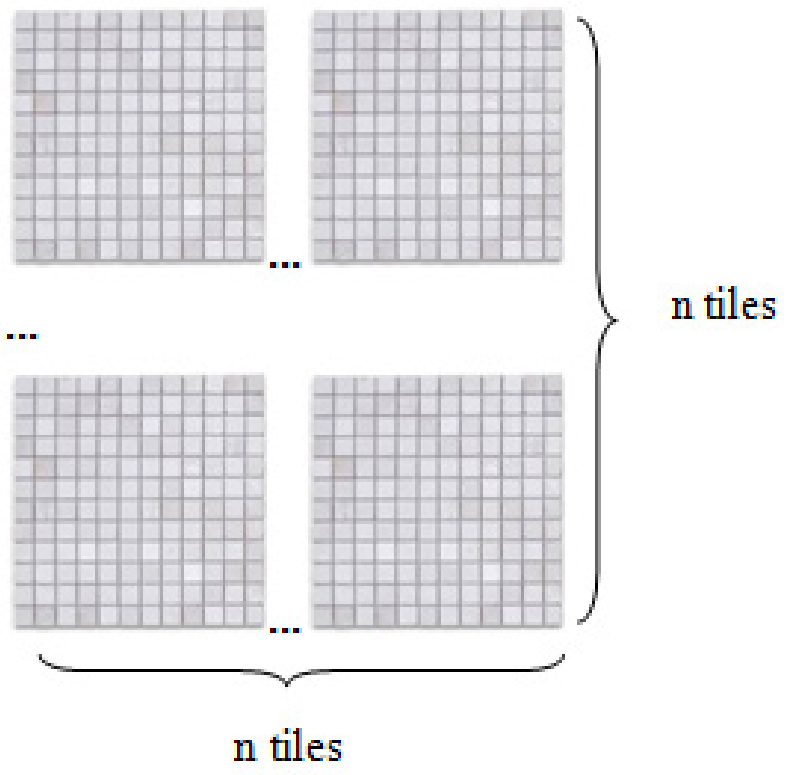

Figure 5. Square assembled by $n \times n$ square tiles on a plane

The teacher let the students observe following these questions:

Figure 5 shows a square assembled by $\mathrm{n}^{2}$ square tiles on a plane.

1. Please count and compare the number of tiles on one side and the number of tiles on a diagonal

2. Please state the general problem in situation 1

3. A rectangle made up of rectangular tiles of length (a) and width (b) so that the number of tiles on the length side of the big rectangle is equal to the number of tiles calculated by the width of the big rectangle. What is the same problem in Figure 6? 


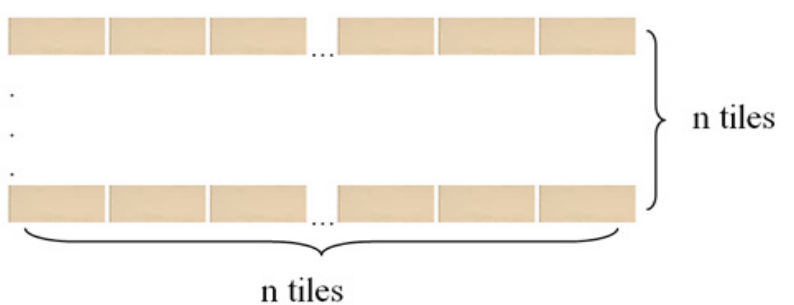

Figure 6. A rectangle made up of rectangular tiles

Question 2 expects students to come up with the general proposition: A square made up of $\mathrm{n} 2$ tiles of the same size (Figure 5). Then the general proposition is stated as follows: In a square given by (Figure 5) the number of tiles per side is equal to the number of tiles on a diagonal.

Indeed, the length of the sides of the square shown in Picture 5 is (na) 2. Let $x$ be the diagonal length. Then, according to Pythagorean Theorem, we have

$$
x^{2}=(n a)^{2}+(n a)^{2}=2 n^{2} a^{2} \Leftrightarrow x=n \sqrt{2} a .
$$

From there, the diagonal length of the square given in Figure 5 is $x=n \sqrt{2} a$.

So $x$ equals the sum of all the lengths of the $n$ diagonal of the squares or in other words the number of tiles calculated on the diagonal of the square represented in Figure 5 is $n$.

Similarly, we can state the correct proposition for Figure 6 as follows: "The number of tiles calculated according to the length or width of the rectangle given in Figure 6 is equal to the number of tiles on the diagonal of that rectangle"

When explaining the specific process for teaching concepts and teaching using the theorem, we have used the expression Figure. Here the representation is understood as the actual representation.

According to Tadao Nakahara [31], representation in mathematics education includes the following 5 types

- Actual representation: Representations are based on the actual state of the object. This type of representation is direct, very specific and natural.

- Performable material representations are teaching aids. It is replacement or mockups of objects that students can directly influence. This kind of representation is impactful, somewhat concrete, and fake.

- Language Representations are representations that use everyday language to express (speak or write). This type of representation is dominated by conventions, but lacks brevity, concise; on the other hand, this representation is descriptive and can create a sense of familiarity.

- Image representations are representations using illustrations, diagrams, graphs, charts. This is a visual and dynamic type of representation.

- Symbol representations are representations that use mathematical symbols such as numbers, characters, and symbols.
Representations are a powerful tool for exploring mathematical problems, allowing students to exchange their problem approaches, arguments, and understanding, helping students to see the meaning of math concepts and the relationship between them.

The experimental process consists of many examples; however, in this paper we only give 3 examples. In Example 1 and Example 2, we describe the scenarios and state the scenarios for the expected answer. In Example 3, we concretize teaching and learning in an experimental process.

Example 3. Two objects are hung on a homogeneous metal rod. The first has gravity $P_{1}$; the second has gravity $P_{2}$. These two objects are hung on correspondingly at positions $\mathrm{A}, \mathrm{B}$ placed on the horizontal rod. Locate point $\mathrm{C}$ on the horizontal bar to hang the system of $P_{1}, P_{2}$, so that the metal rod is in a horizontal position.

This situation was selected from a physical phenomenon, solved by the swing arm rule. However, considering the mathematical idea of this situation related to the concept of neutrality, it has a geometric meaning.

The case study was selected through a teacher's inquiry and was selected after taking the steps out of the design process outlined above.

Below, we conduct teaching according to this process with the aim to evoke motivation and create a need for the formation of set of hidden linear equations. In the following, we present the steps of implementing the process of organizing teaching according to the process of applying the integrated case above.

Step 1. Transfer cognitive tasks to students

Please observe fig.7, describe two objects of gravity $P_{1}, P_{2}$ hanging on a homogeneous metal rod of length $\mathrm{d}$ at position $\mathrm{C}$. The situation poses a question: Locate point $\mathrm{C}$ so that when hanging the system of $P_{1}, P_{2}$ the metal rod is in an equilibrium position (horizontal).

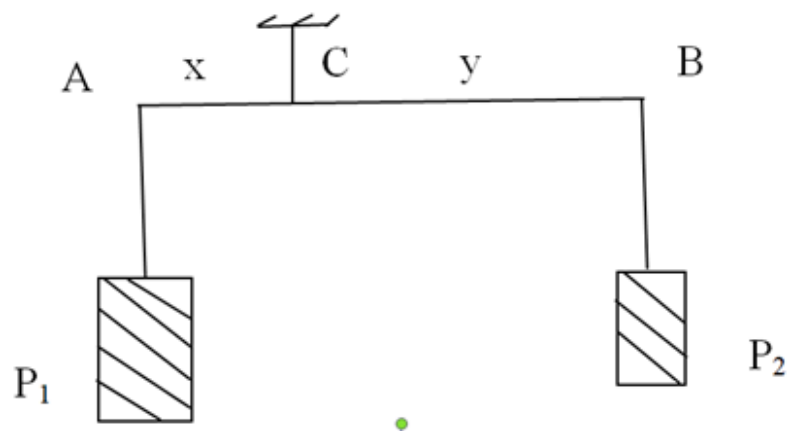

Figure 7. Two objects are hung on a homogeneous metal rod

Step 2. Let students interact with situations to come up with a system of hidden quadratic equations

Let students interact with the situations in 5 groups of 35 students. The teacher gave the following questions or directions:

If the segment $\mathrm{CA}$ is $\mathrm{x}$, and the segment $\mathrm{CB}$ is $\mathrm{y}$, please 
tell us the equation relating to $\mathrm{x}$ and $\mathrm{y}$ according to $P_{1}, P_{2}$. This is a question that reminds students the swing arm rule they learned in Physics.

Answering this question is an opportunity to integrate the physics learned and the math knowledge.

Expected answer: As the swing arm rule, we have $\frac{P_{1}}{P_{2}}=\frac{y}{x}$

Please find the second relation between the two hidden $\mathrm{x}$ and $\mathrm{y}$.

If the length of the segment $A B$ is $d$, what is the relationship between the two unknowns $\mathrm{x}, \mathrm{y}$ ?

Expected answer: $x+y=\mathrm{d}$

At this point, the teacher concludes that to find $\mathrm{x}, \mathrm{y}$ we have the following system of equations:

$$
\left\{\begin{array}{l}
\frac{P_{1}}{P_{2}}=\frac{y}{x} \\
x+y=d
\end{array}\right.
$$

The above system of equations can be written as:

$$
\left\{\begin{array}{l}
P_{1} x-P_{2} y=0 \\
x+y=d
\end{array}\right.
$$

In order for students to generalize to give a system of 2 general hidden linear equations, the teacher might give the following scenario 2 :

A rectangular garden has a circumference of $40(\mathrm{~m})$ and its length is 3 times longer than its width. Calculate the area of that garden.

Học sinh có thể tương tác với tình huống theo các sự kiện chiều dài bằng $\mathrm{x}$; chiều rộng bằng $\mathrm{y}$ và nửa chu vi bằng 20 để có hệ phương trình bậc nhất sau đây:

Students can interact with situations according to x-length, y - width, and 20 (m) of half-perimeter datum to get the following set of linear equation:

$$
\left\{\begin{array}{l}
x+y=20 \\
x-3 y=0
\end{array}\right.
$$

The teacher emphasizes that the above set of equations is a system of hidden first order equations

Considering the two examples above, the teacher asks students to state the general form of the system of hidden first order equations.

The groups are expected to be able to state the general form of the system of hidden first order equations:

$$
\left\{\begin{array}{l}
a x+b y=c \\
a^{\prime} x+b^{\prime} y=c^{\prime}
\end{array}\right.
$$

Step 3. Let students solve 2 systems of equations above and then summarize how to solve general equations

Let students work in groups under teacher's guidance following these questions and orientations

First of all, systemize questions and directions for the system of equations (I)

$$
\left\{\begin{array}{l}
P_{1} x-P_{2} y=0 \\
x+y=d
\end{array}\right.
$$

Is it possible to return the equation (1) of the system (I) to the hidden first-order form and how?

- Can you analyze the equation (2) of the system to find the answer?

Following these direction students can perform $y=d-x$. From there, students know to replace $\mathrm{y}$ by $\mathrm{d}-\mathrm{x}$ into equation (1) to get the hidden first order equation to find $\mathrm{x}$, then we have $P_{1} x-P_{2}(d-x)=0$. Students have already known how to solve this equation.

Then they can find $x=\frac{P_{2} d}{P_{1}+P_{2}}$ Substituting $\mathrm{x}$ for equation

(2) we find $y=\frac{P_{1} d}{P_{1}+P_{2}}$.

Thus, the solutions of the aforementioned systems of equations are conducted using the substitution of $y$ through $\mathrm{X}$.

From there, we conclude that the distance between point $\mathrm{C}$ and $\mathrm{A}$ is $x=\frac{P_{2} d}{P_{1}+P_{2}}$.

Ask students to solve the system of equations (II) using the above substitution and then get the area of the rectangular garden, it is $75 \mathrm{~m}^{2}$.

Ask students to state how to solve the general hidden first order system $2\left\{\begin{array}{l}a x+b y=c \\ a^{\prime} x+b^{\prime} y=c^{\prime}\end{array}\right.$ by substitution. From there, the teacher summarized the steps as follows

Step 1: Using the substitution rule converts a given system of equations into a new system in which the one-hidden equations are presented.

Step 2: Solve this one-hidden equation and deduce the system's root.

Step 4 Guide students to solve the set of equations above in another way

For example, guide students to solve systems of equations

$$
\left\{\begin{array}{l}
P_{1} x-P_{2} y=0 \\
x+y=d
\end{array}\right.
$$

Students can be organized for self-study at home according to the following questionnaires and instructions:

- Is there any solution to turn equation (1) back to the 1 hidden equation without using substitution?

- To answer the above question, we can transform the system of equations

$$
\left\{\begin{array}{l}
P_{1} x-P_{2} y=0 \\
x+y=d
\end{array}\right.
$$

by multiplying the two sides of equation (2) by $P_{2}$.

$$
\left\{\begin{array}{l}
P_{1} x-P_{2} y=0 \\
P_{2} x+P_{2} y=d
\end{array}\right.
$$

From there, adding on the sides of the last 2 equations we have a new system: 


$$
\left\{\begin{array}{l}
P_{1} x-P_{2} y=0 \\
\left(P_{1}+P_{2}\right) x=d
\end{array}\right.
$$

Then, students can easily find $\mathrm{x} ; \mathrm{y}$.

The method of solving the system of equations as above is called the algebraic addition method.

- Similar to the above solution, students solve the system of equations (II) and state how to solve the system of general hidden first order equations according to the algebraic rule.

The situations considered above are intended to describe the process steps using conceptual design and rule situations. Allan B.I. Bernardo [32] state that, the trouble students have with solving problems often comes from the difficulty in understanding the problem structure embedded in the problem text.

\subsection{Data Analysis}

The research team observed learning activities of students from groups influenced and not influenced by integrated teaching for 3 weeks. The assessments will be given after the research team has discussed with the teachers directly teaching, studying the assessment results from the test, studying the learning products. Furthermore, we highly appreciate the issue of performance and advocacy by students. This is a basis for us to determine whether students have mastered math knowledge, as well as improving solving skills in real context.

For teachers participating in experimental and control classes, we all consulted and asked them to evaluate their own teaching activities with the highest fidelity through designed Rubric.

Statistics in Maths was used by the research team to evaluate the math learning results of students taught by integrated method compared with students learned by traditional methods.

\subsection{Procedure}

Two control classes are assigned learning by the teacher's integrated teaching method, while the other two classes are assigned learning by the traditional teaching method that the teacher is still working on daily. The management of learning activities in all four classes remains the same. Test tools include topics (applying geometrical knowledge to life) that were taught during the research.
The first test was administered on the first day of the test period for both the test and control classes; and then, at the end of each week, the same test was administered as a learning progress test. At each learning stage, the items of the test have been rearranged to give the impression that the previous test, the post test, and the delayed posttest are different. Two weeks after administering the test, delayed posttest was implemented to answer the question of whether students remember facts and information or whether their understanding of mathematical concepts and integrating mathematics (geometry) taught by teachers, using different teaching methods influence memorization, understanding and manipulation.

\section{Results}

Before conducting the experiment, we looked at the academic records of all students of the two groups (they were offered by the teachers in charge of the groups), we found that the initial screening of Schools and teachers are good, students are classified according to groups whose math competencies are roughly similar.

After 3 weeks of experiment, we had to test again because the previous analysis method indicated by experts is not convincing. We had to extend the testing period by 3 weeks and re-evaluate according to the experts' comments. Here are the results:

\section{Findings from results of the first test:}

For the pre-test, the score spectra in both groups were very similar (Table 1), where scores $0,8,9$ and 10 were not present in both groups. There are 25 students in group 1 and 25 students in group 2, who got scores of 0, 1, 2 and 3; group 1 has 9 students of 4 , group 2 has 10 students of 4 ; 17 students of group 1 and 22 students of group 2 got scores of 5; 18 students of group 1 and 19 students of group 2 got scores of 6 . Overall, we found that the students' math proficiency demonstrated on the first test did not differ between the two groups.

There was no statistically significant difference of the students in the integrated learning method experiment group and the learning group with the traditional method with "before starting the experiments" (Table 1). It is suggested that students have the same ability to learn Math before being influenced by the teacher's integrated teaching method.

Table 1. Summary table of the first pre-test result

\begin{tabular}{|c|c|c|c|c|c|c|c|c|c|c|c|}
\hline \multirow{2}{*}{ Group } & \multicolumn{11}{|c|}{ Score } \\
\hline & $\mathbf{0}$ & 1 & 2 & 3 & 4 & 5 & 6 & 7 & 8 & 9 & 10 \\
\hline Group 1- First test & 0 & 0 & 10 & 15 & 9 & 17 & 22 & 4 & 0 & 0 & 0 \\
\hline Group 2- First test & 0 & 1 & 11 & 13 & 10 & 18 & 19 & 5 & 0 & 0 & 0 \\
\hline
\end{tabular}




\section{Findings from results of the second test:}

For group 1, we compare the test scores of the first and second test

Based on the results of the second test (Table 1 and Table 2), and compared with the first test, it was found that there is a small change but does not make a clear change in the improvement in math competency of students in group 1. For each group of scores on the first and second tests we did not notice a decrease in math competency. Specifically, on the first test, scores 0 and 1 are not available, but on the second test there is a test of 1 ; With a test of 2, on the first and second test there are 10 and 9 students respectively; similarly with score 3, there are 15 and 14 students respectively; For score 4, the first time has 9 students, and the second has 10 ones; With the score 5 and 6 we saw that in two tests of group 1 all have the same results; For score 7, first test has 4 students, and second test has 7 students (with increases); and there has been a student with 8 , no 9 and no 10. That is, there is an upward but very little change in math competencies among students in group 1 .

For group 2, we compare the test scores of the first and second test

Based on the table comparing scores in group 2 over two tests (Table 3), a significant change in the distribution of scores, in particular, the number of tests scored below 5 (down from 35 tests in first test to 13 in second test); the number of students with score 5 in the first and second test is the same (with 18 students in each test); For score 6 and 7 , there was a significant increase on the second test (from 24 students at 6 and 7 on the first time to 41 students); on the second test, there were 8 and 9 ( 5 students); however, there was no score of 10 .

Table 2. Table comparing the results of the first and second test of group 1

\begin{tabular}{|c|c|c|c|c|c|c|c|c|c|c|c|}
\hline \multirow{2}{*}{ Group } & \multicolumn{11}{|c|}{ Score } \\
\hline & $\mathbf{0}$ & 1 & 2 & 3 & 4 & 5 & 6 & 7 & 8 & 9 & 10 \\
\hline Group 1- First test & 0 & 0 & 10 & 15 & 9 & 17 & 22 & 4 & 0 & 0 & 0 \\
\hline Group 1-Second test & 0 & 1 & 9 & 14 & 10 & 13 & 22 & 7 & 1 & 0 & 0 \\
\hline
\end{tabular}

Table 3. Table comparing the results of the first and second test of group 2

\begin{tabular}{cccccccccccccc}
\hline Group & \multicolumn{1}{c}{ Score } \\
\cline { 2 - 9 } & $\mathbf{0}$ & $\mathbf{1}$ & $\mathbf{2}$ & $\mathbf{3}$ & $\mathbf{4}$ & $\mathbf{5}$ & $\mathbf{6}$ & $\mathbf{7}$ & $\mathbf{8}$ & $\mathbf{9}$ & $\mathbf{1 0}$ \\
\hline Group 2- First test & 0 & 1 & 11 & 13 & 10 & 18 & 19 & 5 & 0 & 0 & 0 \\
Group 2- Second test & 0 & 0 & 2 & 4 & 7 & 18 & 26 & 15 & 3 & 2 & 0 \\
\hline
\end{tabular}

Table 4. Table comparing the results of the second test score of group 1 and group 2

\begin{tabular}{|c|c|c|c|c|c|c|c|c|c|c|c|}
\hline \multirow{2}{*}{ Group } & \multicolumn{11}{|c|}{ Score } \\
\hline & $\mathbf{0}$ & 1 & 2 & 3 & 4 & 5 & 6 & 7 & 8 & 9 & 10 \\
\hline Group 1-Second test & 0 & 1 & 9 & 14 & 10 & 13 & 22 & 7 & 1 & 0 & 0 \\
\hline Group 2- Second test & 0 & 0 & 2 & 4 & 7 & 18 & 26 & 15 & 3 & 2 & 0 \\
\hline
\end{tabular}

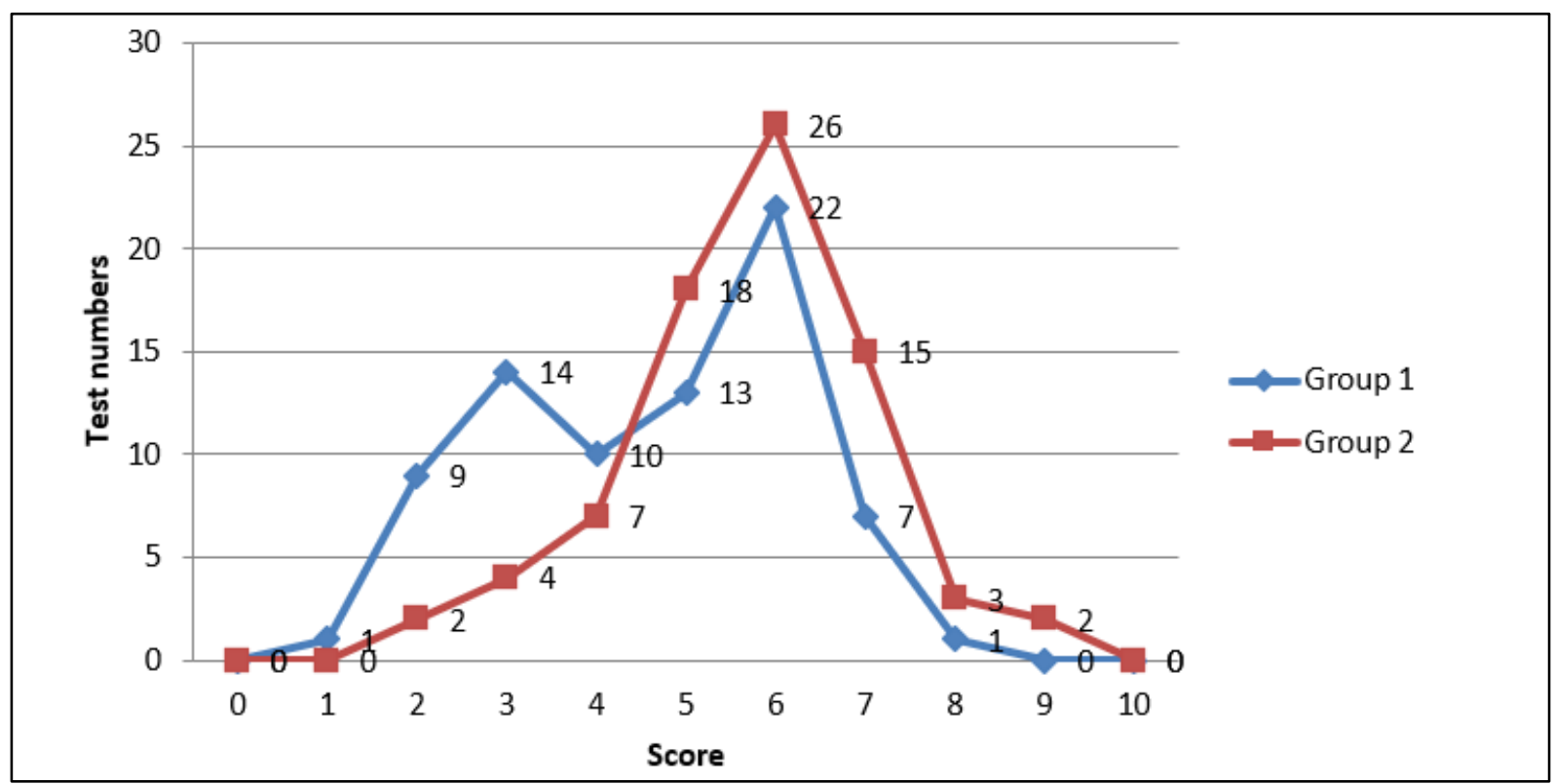

Chart 1. Describe the level of math proficiency of students in group 1 (control group) and group 2 (experimental group) after the assessments (Second test) 
Similarly, we compared the scores between group 2 and group 1 in the second test (Table 4 and Chart 1). The assessment is also assessed by the research team as above, which means that in group 2 (the group is influenced by integrated teaching method) there is a remarkable improvement in mathematical competency compared to group 1 (group learning by traditional methods). We saw a shift in the proportion of scores going forward, the group of scores are below 5 in group 1 (34 students in group 1; 13 students in group 2); group of score 5 in group 1 has 13 students, group 2 has 18 students; group 1 has 22 students with score 6, and group 2 has 26 students; Group 1 has 7 students of 7, and group 2 has 15 students; Particularly for score above 7 , group 1 has 1 student with 8 , while group 2 has 5 students. However, in both groups, there was no score 10.

\section{Findings from results of the third test:}

From Table 5 and Chart 2, we found that group 2 (experimental group) had an improvement in mathematical competency with 15 students under $5 ; 15$ students of $5 ; 35$ students of 6,12 students of 7 . There are 3 students of 8 and above. However, no student has had a score of 10 .

For group 1 (control group), we found that there was no obvious change in scores compared to the first test, with the distribution of scores and the number of students scoring at each grade was almost no change. That is, after three tests, group 1 (control group), we found no significant improvement. Students still have difficulty in problem-solving situations with integration of knowledge, and applying their own experience.

Table 5. The table summarizes the results of 3 tests of group 1 and group 2

\begin{tabular}{|c|c|c|c|c|c|c|c|c|c|c|c|c|}
\hline \multirow{2}{*}{ Test } & \multirow{2}{*}{ Group } & \multicolumn{11}{|c|}{ Score } \\
\hline & & 0 & 1 & 2 & 3 & 4 & 5 & 6 & 7 & 8 & 9 & 10 \\
\hline \multirow{2}{*}{ First test } & Group 1 & 0 & 0 & 10 & 15 & 9 & 17 & 22 & 4 & 0 & 0 & 0 \\
\hline & Group 2 & 0 & 1 & 11 & 13 & 10 & 18 & 19 & 5 & 0 & 0 & 0 \\
\hline \multirow{2}{*}{ Second test } & Group 1 & 0 & 1 & 9 & 14 & 10 & 13 & 22 & 7 & 1 & 0 & 0 \\
\hline & Group 2 & 0 & 0 & 2 & 4 & 7 & 18 & 26 & 15 & 3 & 2 & 0 \\
\hline \multirow{2}{*}{ Third test } & Group 1 & 0 & 1 & 7 & 15 & 18 & 15 & 13 & 7 & 1 & 0 & 0 \\
\hline & Group 2 & 0 & 0 & 0 & 2 & 3 & 12 & 25 & 15 & 9 & 7 & 4 \\
\hline
\end{tabular}

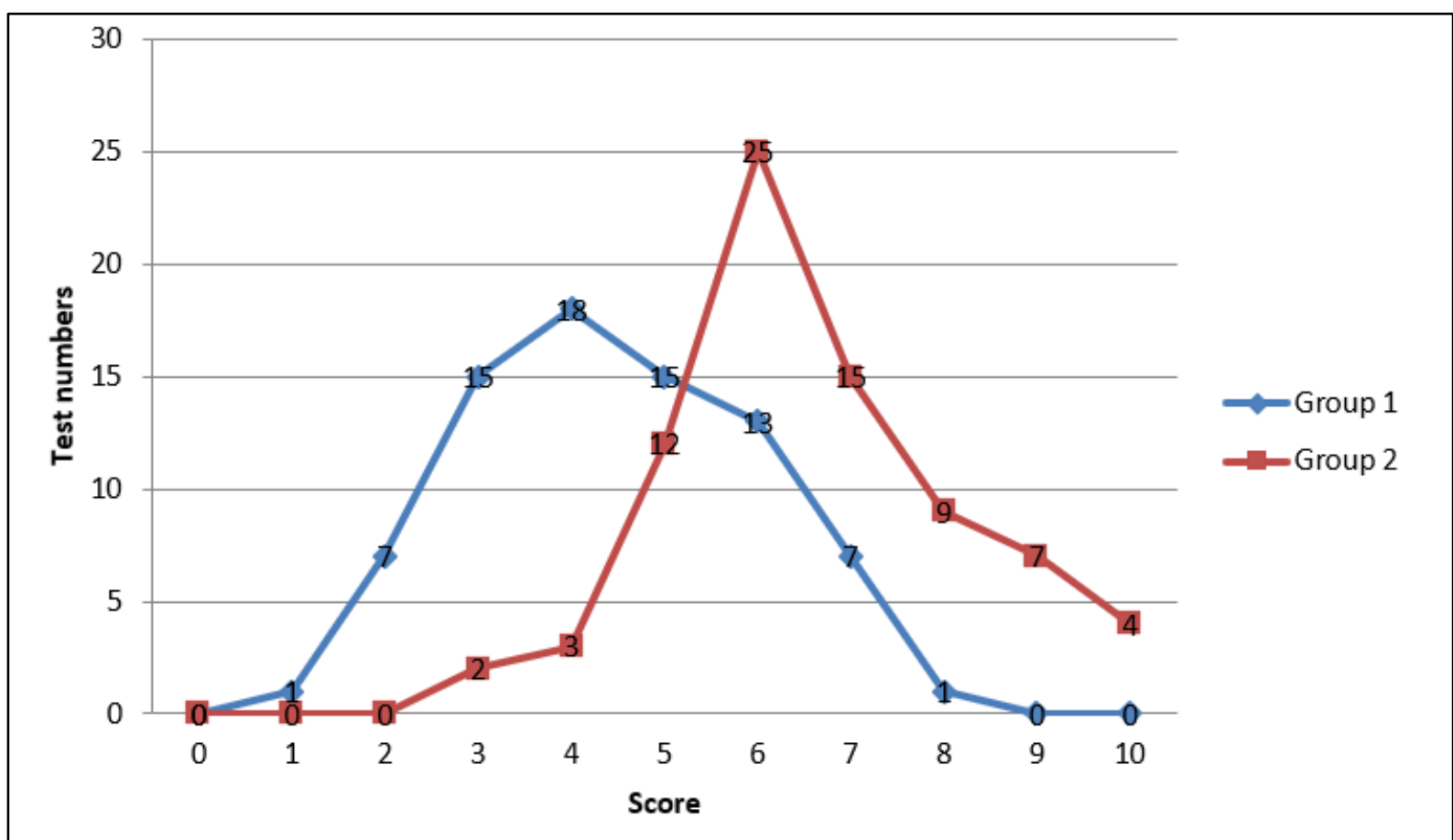

Chart 2. Describe the level of math proficiency of students in group 1 (control group) and group 2 (experimental group) after the assessments (Third test) 
The results of the findings indicated that there was an improvement in pre-test and Delayed Posttest outcomes of groups by integrating the method. Their scores in Topic 1 and 2, at the test level, are higher than their scores in comparison to their classmates in group of traditional method. Similar to the trend that occurred in the Delayed Posttest, students in the learning group by the integrated method were able to retain $80 \%$ of the concepts taught compared to their classmates in the group learning by tradition method (only 10\%). In view of the above findings, this study was able to determine that the hypothesis was accepted because there was a statistically significant difference for the sample's test and the Delayed Posttest in which Students received appropriate pedagogy to score higher than their peers in the conventional group lecture.

For teachers teaching with traditional methods, they recognize that their lessons are really monotonous; teachers must always be active and participate in the whole learning process. They themselves also find that the lesson does not attract students. Students are always passive and receive knowledge in a forced way and unable to create excitement; students can hardly memorize knowledge, and cannot apply to practical situations.

In contrast, for teachers involved in experimental and control classes, through self-assessment Rubics, we get their own observations. 8 out of 10 teachers engaged in teaching stated that they fully completed the task, used the methods and made the mathematical content interpretation much better than the methods indicated for this level. D.V.N (he is a teacher who has been teaching for more than 30 years in high schools, is one of the experts in drafting the general education program in Vietnam) shared that integrated teaching has helped teachers bring math content closer to learning and application. Learning math not only helps students solve math problems but also helps students learn how to solve problematic situations in real context. Teacher B.T.D says that the integrated lesson effectiveness is undeniable; however, she herself finds it difficult to prepare a quality lecture. This requires teachers to be more active in their own teaching.

\section{Findings}

Integrated teaching methods enhance students' efficiency, confidence and interest in mathematics, facilitate an integrated understanding of science, technology, engineering, and mathematics, and nurture creative talent.

The integrated teaching method in secondary schools in Vietnam has tried to improve the students' ability to solve problematic situations in a practical context that bring many practical values to students.

Middle school age is considered to be an important stage in the development of students' values and interests. Therefore, a better understanding of the development of integrated education is needed and students' exploration of integrated learning is needed. This paper contributes to the development of the ability to connect practical situations with mathematical application.

The findings of this study demonstrate the importance of developing the values and benefits of integrated education for students and developing an integrated education program based on a variety of topics pertaining to life around us.

\section{Conclusions}

The findings of this study are consistent with the research results of Saigo [33], White [34], Brad [35] and Venville, G., Rennie, L. \& Wallace, J. [16] stated that, when students were performing open-ended tasks, they drew on a wider variety of knowledge sources than when they were performing less open tasks. Therefore, if education experts build learning approaches that can be used by teachers with integrated teaching methods at secondary schools in Vietnam, there will be an improvement in learning outcomes on how they receive knowledge and apply knowledge to solve situations in life. Through integrated learning, students will develop an active interest in core science subjects at the middle school level that will ultimately expose students to science-oriented courses at learning level behind. In this view, teachers should combine teaching based on empirical strategy of learning integrated learning methods into their teaching methods.

\section{REFERENCES}

[1] Donna Mathewson Mitchell, "Thinking through practice: exploring ways of knowing, understanding and representing the complexity of teaching", Asia-Pacific Journal of Teacher Education, 41:4, 414-425, 2013, DOI: 10.1080/1359866X.2 013.838618

[2] Peter Rawlins, Glenda Anthony, Robin Averill \& Michael Drake, "Novice teachers' perceptions of the use of rehearsals to support their learning of ambitious mathematics teaching", Asia-Pacific Journal of Teacher Education, 2019, DOI: 10.1080/1359866X.2019.1644612

[3] Lu, Yi-Ling and Wu, Chih-Wei, "An Integrated Evaluation Model of Teaching and Learning", Journal of University Teaching \& Learning Practice, 15(3), 2018, Available at:https://ro.uow.edu.au/jutlp/vol15/iss3/8

[4] Benbow, Ronald M., "Tracing Mathematical Beliefs of Preservice Teachers through Integrated Content-Methods Courses". Paper presented at the Annual Meeting of the American Educational Research Association (Atlanta, GA, April 1993).

[5] Barr, R., "Conditions influencing content taught in nine fourth-grade mathematics classrooms", Elementary School Journal, 88, pp. 387-411, 1988. 
[6] Cooney, T.J., “A beginning teacher's view of problem solving", Journal for Research in Mathematics Education, 16, pp. 324-336, 1985.

[7] Grant, C.E., "A study of the relationship between secondary mathematics teachers' beliefs about the teaching-learning process and their observed classroom behaviors", Doctoral dissertation, University of North Dakota. Dissertation Abstracts International, 46, DA8507627, 1984.

[8] Stodolsky, S.S., "Telling math: Origins of math aversion and anxiety”, Educational Psychologist, 20, pp. 125-133, 1985.

[9] Thompson, A., "The relationship of teachers conceptions of mathematics and mathematics teaching to instructional practice", Educational Studies in Mathematics, 15, pp. 105-127, 1984.

[10] Khodaparast Haghi A., "New perspectives in engineering education: the promotion of traditional models to innovative solutions", Journal of Engineering Education, 7(28), pp. 1122. Persian, 2005

[11] Brason J., "Speaking at the Balanced Scorecard Collaborative Conference on Human Capital". Florida: Naples, 2002.

[12] Choi, D.G., de Vries, H.J., "Standardization as emerging content in technology education at all levels of education", Int J Technol Des Educ 21, pp. 111-135, 2011, https://doi.org/10.1007/s10798-009-9110-z

[13] Herbst, Patricio and Chazan, Daniel, "Research on Practical Rationality: Studying the justification of actions in mathematics teaching," The Mathematics Enthusiast: Vol. 8 : No. 3 , Article 2, 2011, Available at: https://scholarworks.u $\mathrm{mt}$. edu/tme/vol $8 /$ iss $3 / 2$

[14] Bredekamp, S. \& Rosegrant, T. (Eds), "Reaching potentials: Appropriate curriculum and assessment for young children", Volume 1. Washington, DC: National Association for the Education of Young Children, 1992.

[15] Katariina Stenberg, Antti Rajala \& Jaakko Hilppo, "Fostering theory-practice reflection in teaching practicums", Asia-Pacific Journal of Teacher Education, 44:5, pp. 470-485, 2016, DOI: 10.1080/1359866X.2015.11 36406

[16] Venville, G., Rennie, L. \& Wallace, J., "Decision Making and Sources of Knowledge: How Students Tackle Integrated Tasks in Science, Technology and Mathematics", Research in Science Education 34, pp. 115-135, 2004, https://doi.org/10.1023/B:RISE.0000033762.75329.9b

[17] Giang Ngoc Nguyen, "Integrated Teaching of Extreme Geometric Problems in Vietnam", International Journal of Learning, Teaching and Educational Research, Vol 18, No 8, pp.168-191, 2019.

[18] Dean, Bonnie A., "Book Review: Integrative Learning International Research and Practice", Journal of University Teaching \& Learning Practice, 12(3), 2015, Available at:https://ro.uow.edu.au/jutlp/vol12/iss3/10

[19] Thompson, P. W., "Experience, problem solving, and learning mathematics: Considerations in developing mathematics curricula", In E. A. Silver (Ed.), Teaching and learning mathematical problem solving: Multiple research perspectives (pp. 189-243), 1985.
[20] General Education Program 2018, Ministry of Education and Training, Vietnam, 2018

[21] Zeynep Çiğdem Özcan, “The relationship between mathematical problem-solving skills and self-regulated learning through homework behaviours, motivation, and metacognition", International Journal of Mathematical Education in Science and Technology, 47:3, pp. 408-420, 2016, DOI: 10.1080/0020739X.2015.1080313

[22] María Jesús Rodríguez, Triana Alejandra Martínez Monés Juan I. Asensio Pérez Yannis Dimitriadis. Scripting and monitoring meet each other: Aligning learning analytics and learning design to support teachers in orchestrating CSCL situations. British Journal of Educational Technology, Volume 46, Issue 2. https://doi.org/10.1111/bjet.12198

[23] Ericade Vries, "Students' construction of external representations in design-based learning situations", Learning and Instruction, Volume 16, Issue 3, June, pp. 213-227, 2006, https://doi.org/10.1016/j.learninstruc.2006.0 3.006

[24] Cai, J., Nie, B., "Problem solving in Chinese mathematics education: research and practice", ZDM Mathematics Education 39, pp. 459-473, 2007, https://doi.org/10.1007/s 11858-007-0042-3

[25] Lubienski, S., "Problem Solving as a Means toward Mathematics for All: An Exploratory Look through a Class Lens", Journal for Research in Mathematics Education, 31(4), pp. 454-482, 2000, doi:10.2307/749653

[26] James Hiebert, Thomas P Carpenter, Elizabeth Fennema, Karen Fuson, Piet Human, Hanlie Murray, Alwyn Olivier, Diana Wearne, "Problem Solving as a Basis for Reform in Curriculum and Instruction: The Case of Mathematics", SAGE Journals, Volume: 25 issue: 4, pp. 12-21., 1996, https://doi.org/10.3102/0013189X025004012

[27] Chen, C.-H., \& Chiu, C.-H., "Employing intergroup competition in multitouch design-based learning to foster student engagement, learning achievement, and creativity". Computers \& Education, 103, 99-113, 2016. https://doi.org/10.1016/j.compedu.2016.09.007

[28] Järvinen, E., Twyford, J., “The Influences of Socio-cultural Interaction upon Children's Thinking and Actions in Prescribed and Open-Ended Problem Solving Situations (An Investigation Involving Design and Technology Lessons in English and Finnish Primary Schools)”. International Journal of Technology and Design Education 10, pp. 21-41, 2000. https://doi.org/10.1023/A:1008996305565

[29] Klug J, Bruder S, Kelava A, Spiel C, Schmitz B., "Diagnostic competence of teachers: A process model that accounts for diagnosing learning behavior tested by means of a case scenario". Teaching and Teacher Education. 30: pp. 38-46, 2013, https://doi.org/10.1016/j.tate.2012.10.004

[30] Haara, Frode Olav; Bolstad, Oda Heidi; Jenssen, Eirik S., "Research on Mathematical Literacy in Schools--Aim, Approach and Attention", European Journal of Science and Mathematics Education Vol. 5, No. 3, pp. 285-313, 2017

[31] Tadao Nakahara, "Development of Mathematical Thinking through Representation: Utilizing Representational Systems", Progress report of the APEC project "Collaborative studies on Innovations for teaching and Learning Mathematics in Different Cultures (II) -Lesson 
Study focusing on Mathematical Communication". Specialist Session, December 2007, University of Tsukuba, Japan.

[32] Allan B.I. Bernardo, "Overcoming Obstacles to Understanding and Solving Word Problems in Mathematics", Educational Psychology, 19:2, pp. 149-163, 1999, DOI: $10.1080 / 0144341990190203$

[33] Saigo BW., "A Study to Compare Traditional and Constructivismbased Instruction of a High School Biology Unit on Biosystematics", Unpublished Doctoral Dissertation: University of IOWA, IOWA City, 1999.

[34] White JH., "Constructivism in a College Biology Classroom: Effects on Content Achievement, Cognitive Growth, and Science Attitude of act-Risk Students". Unpublished Doctoral Dissertation, North Carolina State University, Raleigh, 1999.

[35] Brad H., "Teacher-Centered Instruction versus Student-Centered Instruction", Am. Sch. Board J. pp. 1-5, 2000 .

[36] JS Pang, R Good, "A review of the integration of science and mathematics: Implications for further research", School science and mathematics. Volume100, Issue2, Pages 73-82, 2010.

[37] Olha Matiash, Liubov Mykhailenko , "Opportunities for Method Competence Development of Mathematics Teachers: The Role of Participation in Competitions with Colleagues," Universal Journal of Educational Research,
Vol. 8, No. 3, pp. 747 - 754, 2020. DOI: 10.13189/ujer.2020.080303.

[38] David Gutiérrez-Rubio, Carmen León-Mantero, Alexander Maz-Machado , María José Madrid-Martín , "Relationship between Math Anxiety and Perception of the Utility of Geometry in Primary Education in Prospective Teachers," Universal Journal of Educational Research, Vol. 8, No. 3, pp. 731 - 738, 2020. DOI: 10.13189/ujer.2020.080301.

[39] Meti Widiawati, Anesa Surya , Siti Istiyati, Sukarno , "Error Analysis of Fifth-Grade Students of Elementary School in Geometry Problem Solving Based on Newman's Procedure," Universal Journal of Educational Research, Vol. 8, No. 5, pp. 1676 - 1682, 2020. DOI: 10.13189/ujer.2020.080503.

[40] Valoyes-Chávez, L. On the making of a new mathematics teacher: professional development, subjectivation, and resistance to change. Educ Stud Math (2019) 100: 177. https://doi.org/10.1007/s10649-018-9869-5

[41] Nguyen Huu Hau, Tran Viet Cuong, Tran Trung Tinh. "Students and teachers' perspective of the importance of arts in steam education in Vietnam." Journal of Critical Reviews 7.11 (2020), 666-671. Print. doi:10.31838/jcr.07.11.121

[42] Tran, C. V. "Organizing Project Based Teaching in the Training of Math Teachers in Vietnam," Revista Romaneasca pentru Educatie Multidimensionala, 9(2), 9-35. DOI: http://dx.doi.org/10.18662/rrem/2017.0902.01 